Palavras chave:

Proteína

Braúna

Deterioração

Condutividade

Histórico:

Recebido 06/07/2012

Aceito 18/08/2014

Keywords:

Protein

Braúna

Deterioration

Conductivity

Correspondência: elborges@ufv.br
Eduardo Euclydes de Lima e Borges', Andressa Vasconcelos Flores², Glauciana da Mata Ataíde ${ }^{3}$, Antonio Cesar Batista Matos'

\section{ALTERAÇÕES FISIOLÓGICAS E ATIVIDADE ENZIMÁTICA EM SEMENTES ARMAZENADAS DE Melanoxylon brauna Schott.}

RESUMO: A temperatura e a umidade relativa estabelecem as condições fundamentais na conservação de sementes, quer sejam recalcitrantes, quer sejam ortodoxas. A conservação de sementes de braúna sob umidades relativas de 55,75 e $93 \%$ e temperatura de $20^{\circ} \mathrm{C}$ foi realizada com os objetivos de avaliar as respostas da germinação e do vigor, relacionandoas à permeabilidade da membrana, atividade de enzimas, teor e peroxidação de lipídios. A qualidade das sementes decresce com o aumento do teor de água do ambiente, com decréscimo também das atividades das enzimas superóxido dismutase e catalase e aumento da atividade da enzima glicose-6-fosfato desidrogenase. A permeabilidade das membranas é ampliada com o aumento da deterioração das sementes. Não há relação entre as alterações no teor e peroxidação de lipídios e a deterioração das sementes.

\section{PHYSIOLOGICAL AND ENZYME ACTIVITY CHANGES IN STORED SEEDS OF Melanoxylon brauna Schott.}

ABSTRACT: Temperature and relative humidity set the basic conditions for the preservation of recalcitrant and orthodox seeds. The seed conservation of braúna under relative humidities of 55,75 and $93 \%$ at $20^{\circ} \mathrm{C}$ was performed with the aim of evaluating germination and vigor responses, relating them to the membrane permeability, enzyme activity, content and lipid peroxidation. Increasing environment water content decreases seed quality and also decreases the activity of the enzymes superoxide dismutase and catalase, and increases activity of glucose-6-phosphate dehydrogenase. The membrane permeability increases with increasing deterioration of the seeds. There is no relationship between the changes in lipids content and peroxidation and seed deterioration. 


\section{INTRODUÇÃO}

A Melanoxylon brauna Schott, popularmente conhecida como braúna, tem as descrições de ocorrência e importância da madeira descritas por Carvalho (2003) e Lorenzi (1992). Na literatura, não são encontradas informações a respeito da propagação vegetativa para a espécie, sendo a via seminal a única forma relatada até o momento, o que torna fundamental a pesquisa sobre esse insumo, especialmente em relação ao seu armazenamento.

A alteração nas membranas celulares é um dos componentes no complexo de mudanças bioquímicas e fisiológica que ocorrem durante a deterioração das sementes. Corte (2009) e Pinho et al. (2009) detectaram diferença significativa na condutividade elétrica, durante o armazenamento de sementes de Anadenanthera peregrina e de Melanoxylon brauna, respectivamente.

A peroxidação de lipídios tem sido relacionada ao mecanismo de envelhecimento, sendo uma das possíveis razões para explicar a perda da viabilidade durante o armazenamento de sementes (SUNG, 1996), bem como o decréscimo na atividade das enzimas superóxido dismutase e catalase. A redução na atividade da enzima catalase foi associada à perda de qualidade das sementes de Pterogine nitens (ATAÍDE et al., 20I2) e de Melanoxylon brauna (CORTE et al., 20l0b), respectivamente.

Diante da relevância da deterioração das sementes, neste trabalho, objetivou-se avaliar as respostas da germinação e do vigor, relacionando-os à permeabilidade da membrana, atividade de enzimas, teor e peroxidação de lipídios durante o armazenamento de sementes da espécie.

\section{MATERIAL E MÉTODOS}

As sementes de Melanoxylon brauna foram colhidas na região de Leopoldina, MG, em agosto de 2010 e, após secagem ao sol, foram eliminadas aquelas atacadas por pragas e doenças, as imaturas ou deterioradas. As selecionadas, contendo, aproximadamente, 10\% de teor de água, foram acondicionadas em sacos plásticos e armazenadas em câmara fria a $5^{\circ} \mathrm{C}$ e $60 \%$ de umidade relativa (UR) por dois meses, quando se iniciaram os experimentos.

As sementes foram mantidas em dessecadores contendo sais que estabeleceram as UR, conforme Tabela 1, no período de outubro de 2010 a dezembro de $201 \mathrm{l}$.
TABELA 1 Umidades relativas (UR), em porcentagem, em soluções saturadas de sais para a temperatura de $20^{\circ} \mathrm{C}$.

TABLE 1 Relative humidity in percentage (UR) in salt saturated solutions at $20^{\circ} \mathrm{C}$ temperature.

\begin{tabular}{lcc}
\hline \multicolumn{2}{c}{ Sais utilizados } & UR (\%) \\
\hline Nitrato de Cálcio & $\mathrm{Ca}\left(\mathrm{NO}_{3}\right)_{2}$ & 55 \\
Cloreto de Sódio & $\mathrm{NaCl}$ & 75 \\
Monofosfato de Amônio & $\mathrm{NH}_{4} \mathrm{H}_{2} \mathrm{PO}_{4}$ & 93 \\
\hline
\end{tabular}

Amostras de sementes recém colhidas (sem armazenamento - tempo zero) foram usadas como controle e, a cada trinta dias, a partir do segundo mês de armazenamento, foram realizadas as seguintes análises:

Teor de água - determinado em três repetições de 20 sementes por tratamento, segundo o método da estufa a $105 \pm 3^{\circ} \mathrm{C}$ por 24 horas (BRASIL, 2009).

Germinação - sementes foram colocadas para germinar em placas de Petri, forradas duplamente com papel de filtro tipo germitest, umedecido com água destilada, em germinador a $25^{\circ} \mathrm{C}$ e sob luz constante, proporcionadas por quatro lâmpadas tipo universal, luz do dia especial, de 20W, durante 10 dias. A germinação foi determinada pela contagem diária das sementes que emitiram raiz primária, sendo os resultados expressos em porcentagem média. Foram realizadas cinco repetições de 20 sementes por tratamento.

Índice de velocidade de germinação (IVG) - calculado de acordo com a fórmula proposta por Maguire (1962), apresentada na equação 1, onde $n_{i}$ é o número de sementes por dia e $t_{i}$ é o tempo (dias).

$I V G=\sum\left(\frac{n_{i}}{t_{i}}\right)$

Condutividade elétrica - cinco amostras de 50 sementes de cada tratamento foram colocadas em erlenmeyer com $70 \mathrm{~mL}$ de água destilada a $20^{\circ} \mathrm{C}$ por 18 horas, sendo a condutividade elétrica dos lixiviados determinada, utilizando-se condutivímetro MICRONAL, modelo B 330, eletrodo com constante I,0 (WOODSTOCK, 1973).

Porcentagem de lipídios totais - extração realizada em aparelho Soxhlet, segundo procedimentos descritos por Silva (1990).

Peroxidação de lipídios - avaliada por meio da determinação do índice de TBA (ácido tiobarbitúrico) (ARAÚJO, 1995). Os resultados foram expressos em miligramas de malonaldeído (MDA) ( $\mathrm{mmol} \cdot \mathrm{g}^{-1}$ de amostra), após a conversão da absorvância (LEHNER et al., 2008). Foram utilizadas três repetições por tratamento. 
Extração e quantificação das enzimas Catalase (CAT) e Superóxido dismutase (SOD) os extratos enzimáticos brutos para as determinações das atividades das enzimas CAT e SOD foram obtidos, conforme descrito por Peixoto et al. (1999). A atividade da CAT foi determinada pela adição de $100 \mu \mathrm{L}$ do extrato enzimático bruto a $2,9 \mathrm{~mL}$ de um meio de reação constituído de tampão de fosfato de potássio $50 \mathrm{mM}, \mathrm{pH}$ 7,0 e peróxido de hidrogênio 12,5 mM (HAVIR; MCHALE, 1989). O decréscimo na absorvância a $240 \mathrm{~nm}$, à temperatura de $25^{\circ} \mathrm{C}$, foi medido durante o primeiro minuto da reação, sendo a atividade da CAT determinada com base na inclinação da reta após o início da reação. A atividade enzimática específica foi calculada, utilizando o coeficiente de extinção molar de $36 \mathrm{M} \cdot \mathrm{cm}^{-1}$ (ANDERSON et al., 1995) e o resultado expresso em $\mathrm{mmol} \cdot \mathrm{min}^{-1} \cdot \mathrm{mg}^{-1}$ proteína. A atividade da SOD foi determinada conforme Del Longo et al. (1993) e Giannopolitis e Ries (1977). Uma unidade de SOD foi definida como a quantidade da enzima necessária para inibir em $50 \%$ a fotorredução do NBT (BEAUCHAMP; FRIDOVICH, I97I). Para as determinações enzimáticas foram utilizadas três repetições em triplicatas.

Extração e quantificação da enzima Glucose-6-fosfato desidrogenase (G-6-P DH) - A extração e quantificação foram feitas segundo Ribeiro et al. (2007), com modificações: 100 mg de amostra foram maceradas em cadinho gelado em tampão Tris- $\mathrm{HCl}, 50$ $\mathrm{mM}, \mathrm{pH} 7,5$. Após as amostras foram centrifugadas a 20.000 g por 15 minutos, sendo retirado o sobrenadante (extrato bruto), utilizado para a quantificação da atividade enzimática. $\bigcirc$ meio de reação constituiuse de tampão Tris- $\mathrm{HCl}$ 62,5 mM, pH 7,5; $\mathrm{MgCl}_{2}$ 6,25 mM, NADP 10 mM e glicose-6-fosfato 200 mM, sendo todas concentrações finais. A solução foi deixada em banho-maria a $30^{\circ} \mathrm{C}$ por quatro minutos. A leitura foi realizada em $340 \mathrm{~nm}$, por 30 minutos, em intervalo de cinco minutos. Uma unidade da enzima $(U)$ foi definida como a quantidade da enzima necessária para formar I $\mathrm{mM}$ de NADPH$\cdot \mathrm{min}^{-1}$. Foram realizadas três repetições em triplicata.

O delineamento experimental utilizado foi o inteiramente casualizado (DIC) em esquema de parcelas subdivididas. Os resultados foram submetidos à análise de variância (ANOVA), sendo ajustadas equações de regressão com auxílio do software SAEG. Os resultados das variáveis analisadas foram correlacionados, por meio do uso de correlação simples, a 5\%, pelo teste $\mathrm{F}$.

\section{RESULTADOS E DISCUSSÃO}

Em umidade relativa de $55 \%$, o teor de água das sementes permaneceu constante, demonstrando que se encontravam em equilíbrio higroscópico naquele ambiente (Figura 1). No ambiente com $75 \%$ de UR, o aumento inicial do grau de umidade das sementes entrou em equilíbrio no terceiro mês de armazenamento, mas as sementes morreram em sete meses. Por outro lado, o teor de água das sementes em 93\% de UR aumentou até o quarto mês, quando então as sementes morreram, sem alcançarem o equilíbrio higroscópico. Segundo estudos de Borges et al. (2009) para sementes de Anadenanthera peregrina e de Antunes et al. (2010) para sementes de Caesalpinia pyramidalis, as melhores condições de armazenamento são aquelas que envolvem baixas temperatura e umidade relativa.

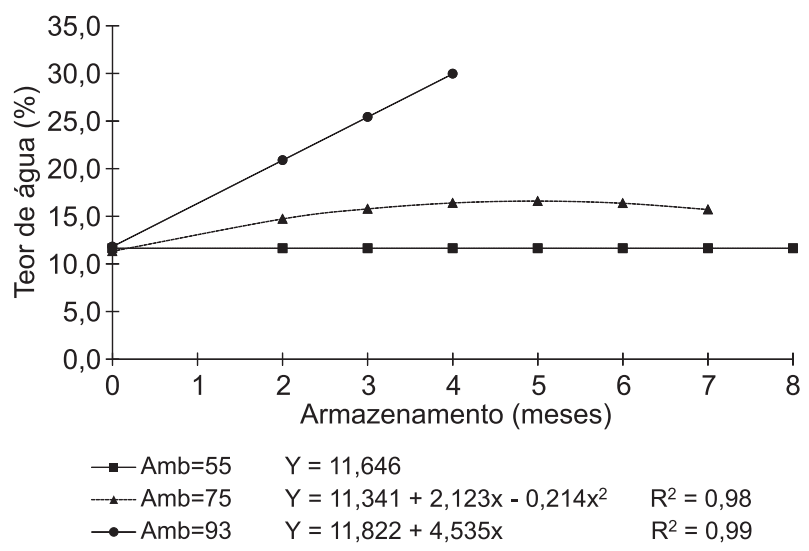

FIGURA 1 Teores de água (\%) de sementes de Melanoxylon brauna durante armazenamento em 55,75 e $93 \%$ de umidade relativa do ar, a $20^{\circ} \mathrm{C}$.

FIGURE 1 Water content (\%) of seeds of Melanoxylon brauna during storage at 55,75 and $93 \%$ relative humidity, at $20^{\circ} \mathrm{C}$.

A germinação e o IVG (Figuras $2 \mathrm{~A}$ e $2 \mathrm{~B}$ ) mantiveram-se sem grandes variações ao longo do tempo de armazenamento quando mantidas em $55 \%$ de UR. Em 75 e $93 \%$ de UR, as condições foram apropriadas para alta atividade metabólica, proporcionada pelo alto teor de água alcançado pelas sementes, associado à temperatura de $20^{\circ} \mathrm{C}$. Em estudo realizado com $\mathrm{M}$. brauna foi observado que a germinação das sementes da espécie ocorre em amplo intervalo de temperatura, o qual inclui a temperatura utilizada no presente trabalho $\left(20^{\circ} \mathrm{C}\right)$ (FLORES, 20II). Dessa forma, tendo condições de temperatura para germinar, mas com teor de água abaixo de nível que permitisse a protrusão radicular, a semente não germina nos ambientes de armazenamento 
75 e $93 \%$ e tende a morrer, em decorrência das condições estressantes de umidade presentes. Nascimento et al. (2010) observaram germinação de sementes de Euterpe oleracea dentro dos recipientes de armazenamento quando alcançaram teor de água de $43,4 \%$ a $20^{\circ} \mathrm{C}$.
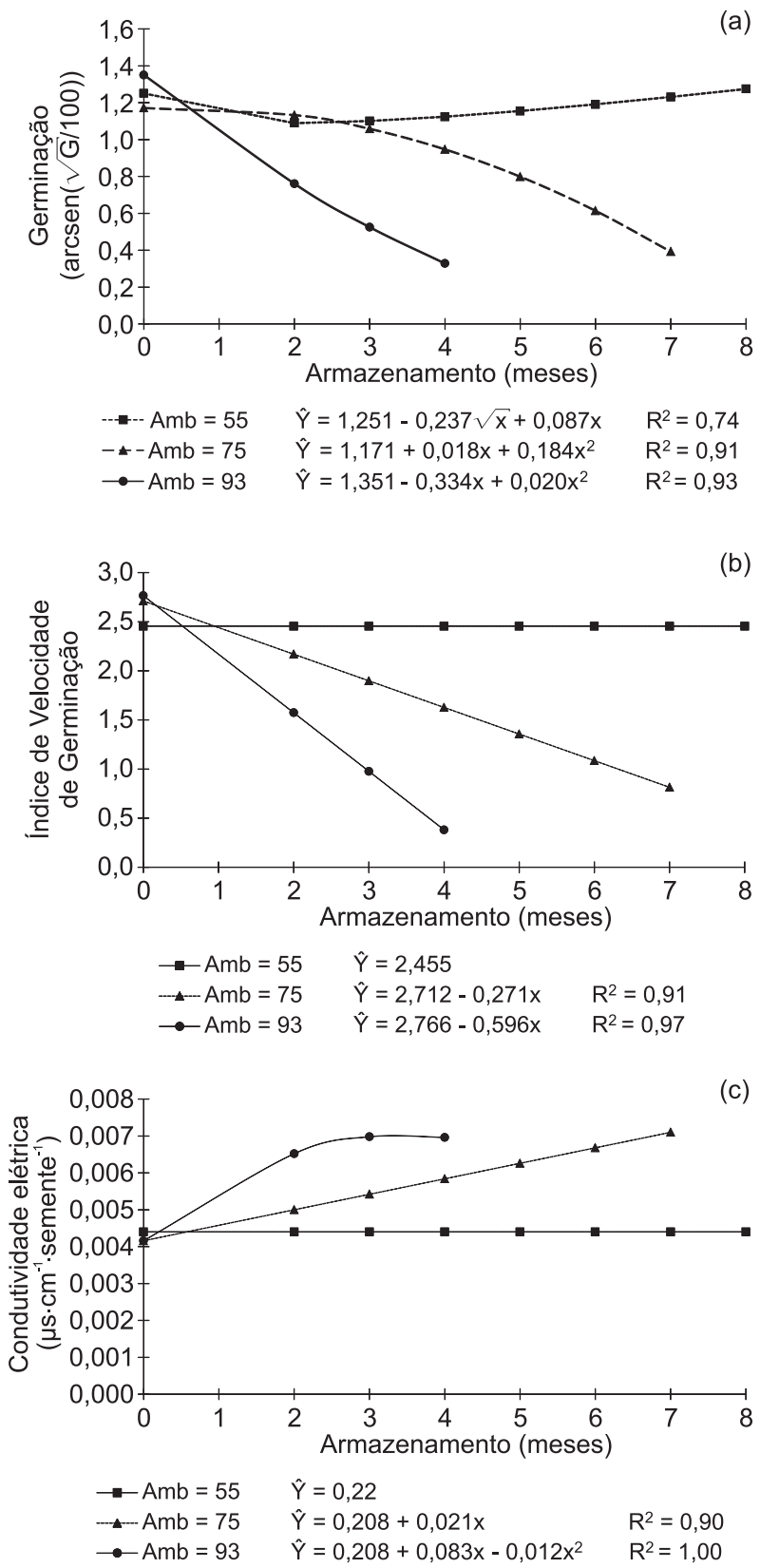

FIGURA 2 Germinação (arcsen $\sqrt{G} / 100)$, índice de velocidade de germinação (IVG) e condutividade elétrica ( $\mu \mathrm{s}$. $\mathrm{cm}^{-1}$. semente $^{-1}$ ) de sementes de Melanoxylon brauna durante o armazenamento em 55, 75 e 93\% de umidade relativa do ar, a $20^{\circ} \mathrm{C}$.

FIGURE 2 Seed germination (arcsen $\sqrt{G} / 100)$, index rate of germination (IVG) and electrical conductivity ( $\mu \mathrm{s}$. $\mathrm{cm}^{-1}$. semente ${ }^{-1}$ ) of Melanoxylon brauna seeds stored at 55,75 and $93 \%$ relative humidity at $20^{\circ} \mathrm{C}$.
As curvas de condutividade elétrica, mostradas na Figura 2C, são compatíveis com os dados de germinação e de IVG, em que as sementes mantidas em $93 \%$ de UR tiveram maior condutividade, seguidas pelas sementes armazenadas sob $75 \%$ e em $55 \%$. Durante a deterioração das sementes, ocorrem modificações na membrana celular, resultando na perda da semipermeabilidade (GOLOVINA et al., 20I0). Dessa forma, as células perdem componentes essenciais do metabolismo para o ambiente (KIKUTI et al., 2008). As alterações na permeabilidade celular estão relacionadas com a deterioração de sementes armazenadas de várias espécies florestais, como, por exemplo, Melanoxylon brauna (CORTE et al., 20I0a) e Plathymenia reticulata (PEREIRA et al., 20I0).

Não foram observadas diferenças significativas entre os teores de lipídios e de peroxidação de lipídios nas sementes mantidas nas diferentes UR (dados não mostrados). Portanto, não se pode afirmar que a utilização, a síntese de lipídios ou a peroxidação estejam relacionadas à perda de qualidade de sementes de $M$. brauna armazenadas. Esses resultados diferem dos resultados obtidos por Corte et al. (20l0b) para a mesma espécie, no qual os autores observaram correlação entre perda de qualidade das sementes com o decréscimo no teor de lipídios. Dessa forma, supõem-se que as alterações nos teores de lipídios sejam relevantes até certo nível de deterioração, não ocorrendo a correlação quando a redução da viabilidade é acentuada.

As atividades da enzima superóxido dismutase decresceram nos três ambientes de armazenamento, especialmente nas sementes mantidas em 93\% de UR (Figura 3A). Em 75\% houve tendência geral de decréscimo com $\bigcirc$ aumento na atividade com três meses de armazenamento e outro no intervalo de quatro a seis meses. A atividade da enzima decresceu continuamente em $55 \%$ de UR, mas também com o aumento, a partir de cinco meses de armazenamento. Nesta, a atividade da enzima manteve-se, de maneira geral, superior àquelas nos demais ambientes. Pelos resultados nos três casos e pelos dados apresentados na Tabela 1, percebe-se a desvinculação da atividade da enzima com o processo deteriorativo das sementes de M. brauna. Uma vez que a atividade não foi afetada pelos ambientes de armazenamento, o processo deteriorativo está, aparentemente, relacionado à formação de radicais superóxido na mitocôndria, onde há utilização de oxigênio no processo respiratório e onde grande parte de EROs é produzido, necessitando de eficiente sistema de desintoxicação (GLEASON, 20I2). 

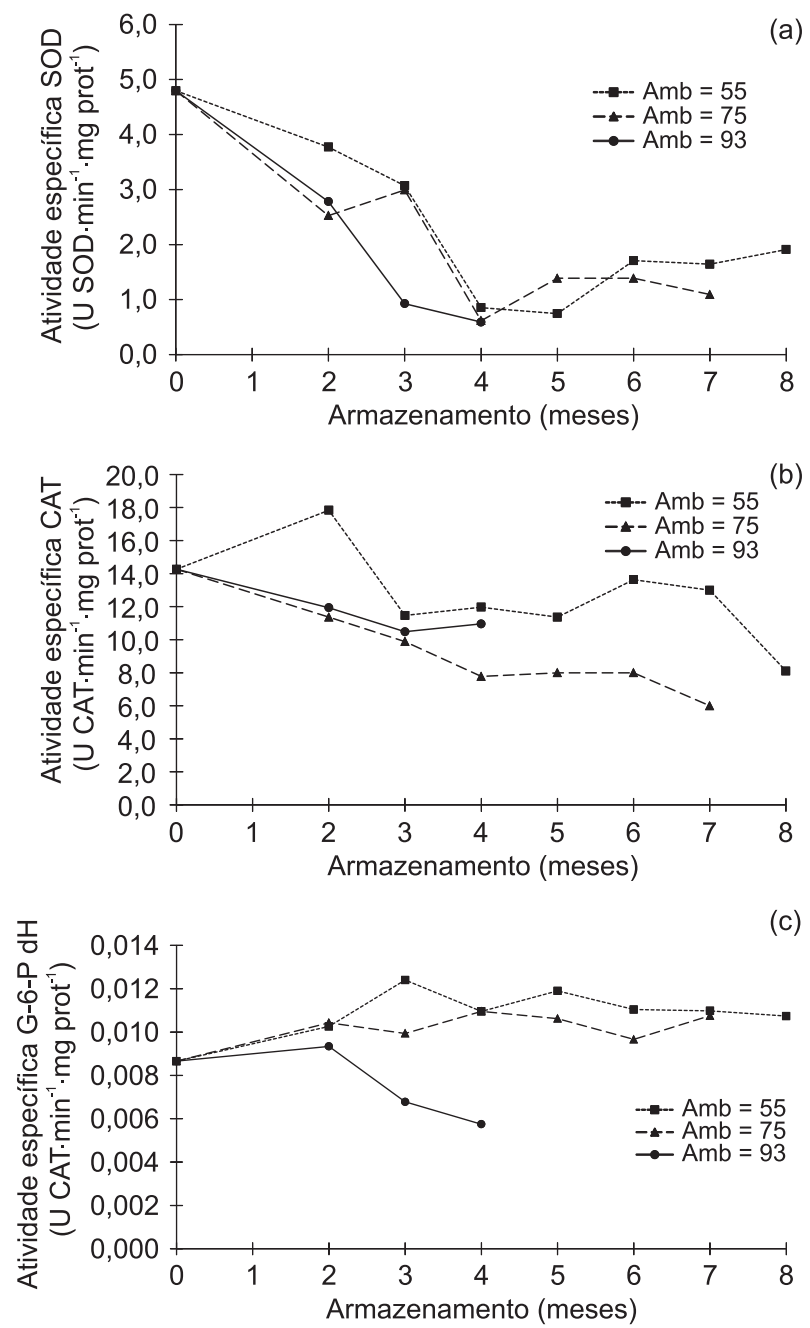

FIGURA 3 Atividade específica das enzimas superóxido dismutase (SOD) (U SOD. $\left.\mathrm{min}^{-1} . \mathrm{mg} \mathrm{prot}^{-1}\right)(\mathrm{A})$, catalase (CAT) (U CAT. $\mathrm{min}^{-1}$. $\left.\mathrm{mg} \mathrm{prot}^{-1}\right)(\mathrm{B}) \mathrm{e}$ glicose-6-fosfato desidrogenase (G-6-P DH) (U G-6-P dH. min $^{-1}$. mg prot ${ }^{-1}$ ) (C) em sementes de Melanoxylon brauna durante o armazenamento 55, 75 e $93 \%$ de umidade relativa do ar, a $20^{\circ} \mathrm{C}$.

FIGURE 3 Specific activity of the enzyme superoxide dismutase (SOD) (U SOD. $\mathrm{min}^{-1}$. mg $\operatorname{prot}^{-1}$ ) (A), catalase (CAT) (U CAT. min ${ }^{-1}$. mg prot $\left.{ }^{-1}\right)(B)$ and glucose-6-phosphate dehydrogenase (G-6-P DH) ( $U$ G-6-P dH. min $^{-1}$. mg prot ${ }^{-1}$ ) (C) of seeds of Melanoxylon brauna during storage at 55, 75 and $93 \%$ relative humidity at $20^{\circ} \mathrm{C}$

A atividade da enzima catalase nas sementes armazenadas em $55 \%$ de UR aumentou em dois meses de armazenamento (Figura 3B), seguido de decréscimo e com pouca variação até o sétimo mês. Aquelas sementes mantidas em 75 e $93 \%$ tiveram decréscimos semelhantes entre si até o terceiro mês, com o valor da atividade nessa última UR, alcançando valores próximos daqueles de 55\%. Pela Tabela 1, percebe-se maior participação da enzima no processo deteriorativo das sementes de braúna. A falta de atuação da SOD e da CAT pode estar sendo compensada, em parte, pela atuação de substâncias antioxidantes, como o ácido ascórbico ou a piridoxina (vitamina B6) (DOLATABADIAN; MODARRESSANAVY, 2008) que, dessa forma, manteriam os valores obtidos de lipídios total e peroxidado sem alterações durante o armazenamento.

Alternativamente, é possível que parte desses resultados possa estar relacionado ao metabolismo dos ácidos graxos no glioxissomo, onde a catalase tem papel fundamental na remoção do peróxido de hidrogênio. Sendo assim, a queda na atividade da enzima não resultaria em maiores consequências no metabolismo de lipídios, pois, mesmo em baixa, seria suficiente para manter o ciclo do glioxalato e prover acetil CoA necessário para usos diversos.

A enzima G-6-P DH teve sua atividade estimulada nos ambientes de 55 e $75 \%$ de UR e estável em $93 \%$, conforme mostrado na Figura 3C. Essa enzima tem sua função no ciclo das pentoses mono fosfatadas, onde são produzidos vários intermediários para outras rotas, especialmente para glicólise. Porém, não se pode afirmar que a rota esteja participando claramente na manutenção ou não da viabilidade das sementes, tendo em vista a morte de sementes mantidas em $93 \%$ UR. Possivelmente, o teor de água das sementes seja suficiente para manter a rota funcionando para atender às necessidades específicas, como a produção de produtos secundários. Martins et al. (20l I) também concluíram que essa enzima não foi eficiente na identificação dos graus de deterioração de sementes de Euterpe espiritosantensis.

Pelos valores de correlação mostrados na Tabela 2, observa-se o aumento das correlações e entre as variáveis germinação, IVG, condutividade elétrica e teor de água, à medida que aumenta a umidade relativa do ambiente de armazenamento, o que demonstra claramente a inter-relação entre os parâmetros. Por outro lado, a Tabela 2 também mostra que as enzimas SOD e CAT exerceram pouca interferência na deterioração, com baixos valores de correlação. Mesmo assim, foram constatadas correlações positivas significativas entre a variável CAT e as variáveis germinação e IVG, a partir de $75 \%$ de UR.

A G-6-P apresentou valores pequenos nas diversas correlações nos ambientes 55 e $75 \%$, mas indicou tendências no comportamento das sementes armazenadas à $93 \%$. O aumento da umidade relativa teve como resultado positivo o aumento em sua atividade em 
relação a aumentos na germinação e IVG (coeficientes de 0,75 para ambas as correlações), significativos a $5 \%$, demonstrando o efeito deletério no metabolismo do armazenamento sob altas URs, acompanhando a redução na qualidade das sementes. Nesse contexto, a atividade dessa enzima somente poderia ser utilizada como indicativo da qualidade das sementes quando o vigor estiver muito baixo, momento em que os seus valores mostraram alterações significativas.

TABELA 2 Coeficientes de correlação simples ( $r$ ) entre os valores médios de germinação $(\mathrm{G})$, índice de velocidade de germinação (IVG), condutividade elétrica (Cond), teor de água (Agua) e atividade das enzimas superóxido dismutase (SOD), catalase (CAT) e glicose-6-fosfato desidrogenase (G6P) em sementes de Melanoxylon brauna durante o armazenamento em umidades relativas de $55 \%(A m b=55), 75 \%(A m b=75)$ e $93 \%$ $(\mathrm{Amb}=93)$ à $20^{\circ} \mathrm{C}$.

TABLE 2 Simple correlation coefficients $(r)$ between the mean values of germination (G), germination speed index (GSI), electrical conductivity (Cond), moisture (Agua) and enzymes superoxide dismutase (SOD), catalase (CAT) and glucose 6-phosphate dehydrogenase (G6P) in seeds of Melanoxylon brauna during storage at relative humidities of $55 \%$ $(\mathrm{Amb}=55), 75 \%(\mathrm{Amb}=75)$ and $93 \%(\mathrm{Amb}=93)$ at $20^{\circ} \mathrm{C}$

\begin{tabular}{|c|c|c|c|c|c|c|c|}
\hline \multicolumn{8}{|c|}{$A m b=55$} \\
\hline & G & IVG & Cond & Agua & SOD & CAT & G6P \\
\hline G & 1,00 & $0,89^{*}$ & $-0,25$ & 0,09 & $-0,08$ & $-0,32^{*}$ & $-0,23$ \\
\hline IVG & - & 1,00 & $-0,30$ & 0,11 & $-0,01$ & $-0,12$ & $-0,41$ \\
\hline Cond & - & - & 1,00 & 0,22 & $-0,30$ & $-0,07$ & 0,22 \\
\hline Agua & - & - & - & 1,00 & $-0,69^{*}$ & $-0,24$ & 0,29 \\
\hline SOD & - & - & - & - & 1,00 & $0,38^{*}$ & $-0,37^{*}$ \\
\hline CAT & - & - & - & - & - & 1,00 & $-0,26$ \\
\hline \multicolumn{8}{|c|}{$A m b=75$} \\
\hline & G & IVG & Cond & Agua & SOD & CAT & G6P \\
\hline G & 1,00 & $0,98^{*}$ & $-0,69^{*}$ & $-0,60^{*}$ & 0,27 & $0,58^{*}$ & $-0,36^{*}$ \\
\hline IVG & - & 1,00 & $-0,75^{*}$ & $-0,70^{*}$ & 0,28 & $0,57^{*}$ & $-0,40^{*}$ \\
\hline Cond & - & - & 1,00 & $0,68^{*}$ & 0,06 & $-0,18$ & $0,36^{*}$ \\
\hline Agua & - & - & - & 1,00 & $-0,23$ & $-0,46^{*}$ & $0,46^{*}$ \\
\hline SOD & - & - & - & - & 1,00 & $0,49^{*}$ & $-0,24$ \\
\hline CAT & - & - & - & - & - & 1,00 & $-0,13$ \\
\hline \multicolumn{8}{|c|}{$A m b=93$} \\
\hline & G & IVG & Cond & Agua & SOD & CAT & G6P \\
\hline G & 1,00 & $0,99^{*}$ & $-0,78^{*}$ & $-0,92^{*}$ & 0,08 & $0,45^{\star}$ & $0,75^{*}$ \\
\hline IVG & - & 1,00 & $-0,84^{*}$ & $-0,95^{*}$ & $-0,02$ & $0,49^{*}$ & $0,75^{*}$ \\
\hline Cond & - & - & 1,00 & $0,94^{*}$ & 0,27 & $-0,56^{*}$ & $-0,48^{*}$ \\
\hline Agua & - & - & - & 1,00 & 0,17 & $-0,58^{*}$ & $-0,62^{*}$ \\
\hline SOD & - & - & - & - & 1,00 & $-0,31$ & $-0,13$ \\
\hline CAT & - & - & - & - & - & 1,00 & 0,08 \\
\hline
\end{tabular}

${ }^{*}=$ valor significativo a $5 \%$, pelo teste $\mathrm{F}$.

\section{CONCLUSÕES}

O vigor das sementes de braúna decresce com o aumento da umidade relativa no ambiente de armazenamento. Há redução das atividades das enzimas antioxidantes na perda de qualidade das sementes.

A perda de semipermeabilidade das membranas celulares relaciona-se com o decréscimo na qualidade das sementes. A enzima glucose-6-fosfato apresenta relação com o estado fisiológico das sementes, apenas quando estas encontram-se em maior estado de deterioração.

\section{AGRADECIMENTOS}

Ao CNPq pelo apoio financeiro.

\section{REFERÊNCIAS}

ANDERSON, M. D.; PRASAD, T. K.; STEWART, C. R. Changes in isozyme profiles of catalase, peroxidase, and glutathione reductase during acclimation to chilling in mesocotyls of maize seedlings. Plant Physiology, Bethesda, v. 109, p. 1247-1257, 1995.

ANTUNES, C. G. C.; CURZ, C. R. P.; RIBEIRO, R. C.; GOMES, H. L. R.; CASTRO, R. D. Influência do armazenamento na qualidade fisiológica de sementes de Caesalpinia pyramidalis Tul. Revista Árvore, Viçosa, v. 34, n. 6, p. I00 I-1008, 2010.

ARAÚJO, J. M. A. Química de alimentos: teoria e prática. Viçosa, MG: UFV, 1995. 335 p.

ATAIDE, G. M.; FLORES, A. V.; BORGES, E. E. L. Alterações fisiológicas e bioquímicas em sementes de Pterogine nitens Tull. durante $\circ$ envelhecimento artificial. Pesquisa Agropecuária Tropical, Goiânia, v. 42, n. I, p. 7I-76, 2012.

BEAUCHAMP, C.; FRIDOVICH, I. Superoxide dismutase improved assays and assay applicable to acrylamide gels. Analytical Biochemistry, Maryland, v. 44, p. 276-287, I97I.

BORGES, S.; BORGES, E. E. L.; CORREA, P. C.; BRUNE, A. Equilíbrio higroscópico e viabilidade de sementes de angico-vermelho (Anadenanthera peregrina (L.) Speng) em diferentes condições ambientais de armazenamento. Scientia Forestalis, Piracicaba, v. 37, n. 84, p. 475-48I, 2009.

BRASIL. Ministério da Agricultura, Pecuária e Abastecimento. Regras para análise de sementes. Brasília, 2009. 399 p.

CARVALHO, P. E. R. Espécies florestais brasileiras: recomendações, silviculturas, potencialidades e uso da madeira. Colombo: EMBRAPA-CNPF; Brasília: EMBRAPASPI, 2003. 638 p. 
CORTE, V. B.; BORGES, E. E. L.; LEITE, H. G.; LEITE, I. T. A. Qualidade fisiológica de sementes de Melanoxylon brauna envelhecidas natural e artificialmente. Scientia Forestalis, Piracicaba, v. 38, n. 86, p. I8I-189, 2010a.

CORTE, V. B.; BORGES, E. E. L.; LEITE, H. G.; PEREIRA, B. L. C.; GONÇALVES, J. F. C. Estudo enzimático da deterioração de sementes de Melanoxylon brauna submetidas ao envelhecimento natural e acelerado. Revista Brasileira de Sementes, Brasília, v. 32, n. I, p. 83-91, 2010 b.

DEL LONGO, O. T.; GONZÁlES, C. A.; PASTORI, G. M.; TRIPPI, V. S. Antioxidant defenses under hyperoxygenic and hyperosmotic conditions in leaves of two lines of maize with differential sensitivity to drought. Plant Cell Physiology, Oxford, v. 34, p. 1023-1028, 1993.

DOLATABADIAN, A.; MODARRESSANAVY, S. A. M. Effect of the ascorbic acid, pyridoxine and hydrogen peroxide treatments on germination, catalase activity, protein and malondialdehyde content of three oil seeds. Notulae Botanicae Horti Agrobotanici, Cluj-Napoca, v. 36, n. 2, p. 6I-66, 2008.

FLORES, A. V. Germinação de sementes de Melanoxylon brauna (Schott) sob diferentes temperaturas: aspectos morfofisiológicos e enzimáticos. 201 I. 66 p. Tese (Doutorado em Ciências Florestais) - Universidade Federal de Viçosa, Viçosa, $201 \mathrm{I}$.

GIANNOPOLITIS, C. N.; RIES, S. K. Superoxide dismutases. Plant Physiology, Rockville, v. 59, p. 309-3।4, 1977.

GLEASON, F. K. Plant biochemistry. Sudbury: Jones \& Bartlett Learning, 2012. 239 p.

GOLOVINA, E. A.; VAN, A. S. H.; HOEKSTRA, F. A. Membrane chemical stability and seed longevity. European Biophysic Journal, Heidelberg, v. 39, p. 657-668, 2010.

HAVIR, E.; MCHALE, N. A. A regulation of catalase activity in leaves of Nicotiana sylvestris by high $\mathrm{CO}_{2}$. Plant Physiology, Bethesda, v. 89, n. 3, p. 952-957, 1989.

KIKUTI, H.; MEDINA, P. F.; KIKUTI, A. L. P.; RAMOS, N. P. Teste de lixiviação de potássio para avaliação do vigor de sementes de amendoim. Revista Brasileira de Sementes, Brasília, v. 30, n. I, p. 10-18, 2008.

LEHNER, A.; MAMADOU, N.; POELS, P.; COME, D.; BAILLY, C.; CORBINEAU, F. Changes in soluble carbohydrate, lipid peroxidation and antioxidant enzyme activities in the embryo during ageing in wheat grains. Journal Cereal Science, Cambridge, v. 47, p. 555-565, 2008.
LORENZI, H. A. Árvores brasileiras: manual de identificação e cultivo de plantas arbóreas nativas do Brasil. Nova Odessa: Plantarum, 1992. 352 p.

MAGUIRRE, J. D. Speed of germination and in selection and evaluation from seedling emergence and vigor. Crop Science, Madison, v. 2, n. 2, p. 176-177, 1962.

MARTINS, C. C.; NAKAGAWA, J.; RAMOS, P. R. R. Isoenzimas no monitoramento da deterioração de sementes de Euterpe espiritosantensis Fernandes. Revista Árvore, Viçosa, v. 35, n. I, p. 85-90, jan. 201 I.

NASCIMENTO, W. M. O.; CICERO, S. M.; NOVEMBRE, A. D. L. C. Conservação de sementes de açaí (Euterpe eleracea Mart.). Revista Brasileira de Sementes, Brasília, v. 32, n. I, p. 24-33, 2010.

PEIXOTO, P. H. P.; CAMBRAIA, J.; SANT'ANNA, R.; MOSQUIN, P. R.; MOREIRA, M. A. Aluminium effects on lipid peroxidation and on the activities of enzymes of oxidative metabolism in sorghum. Revista Brasileira Fisiologia Vegetal, Campinas, v. II, n. 3, p. I37-I43, 1999.

PEREIRA, B. L. C.; BORGES, E. E. L.; OLIVEIRA, A. C.; LEITE, H. G.; GONÇALVES, J. F. C. Influência do óxido nítrico na germinação de sementes de Plathymenia reticulata Benth com baixo vigor. Scientia Forestalis, Piracicaba, v. 38, n. 86, p. $181-189,2010$.

PINHO, D. S.; BORGES, E. E. L.; CORTE, V. B.; BHERING, L. C. Avaliação da qualidade fisiológica de sementes de Anadenanthera peregrina (L.) Speng. durante o armazenamento. Revista Árvore, Viçosa, v. 33, n. I, p. 27-33, jan. 2009.

RIBEIRO, M. Z.; SILVA, D. P.; VITOLO, M.; ROBERTO, I. C.; PESSOA JUNIOR, A. Partial purification of glucose-6phosphate dehydrogenase by aqueous two-phase poly (ethyleneglycol)/phosphate systems. Brazilian Journal of Microbiology, São Paulo, v. 38, p. 78-83, 2007.

SILVA, D. J. Análise de alimentos: métodos químicos e biológicos. Viçosa, MG: UFV, 1990. 165 p.

SUNG, J. M. Lipid peroxidation and peroxide-scavenging in soybean seeds during aging. Plant Physiology, Bethesda, v. 97, p. 85-89, 1996.

WOODSTOCK, L. W. Physiological and biochemical test for seed vigor. Seed Science and Technology, Zurich, v. I, p. 127-157, 1973. 